\title{
Do intrauterine growth restriction and overweight at primary school age increase the risk of elevated body mass index in young adults?
}

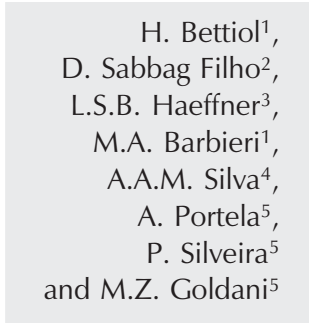

Correspondence

H. Bettiol

Departamento de Puericultura e

Pediatria

FMRP, USP

Avenida Bandeirantes, 3900

14049-800 Ribeirão Preto, SP

Brasil

Fax: +55-16-3602-2700

E-mail: hbettiol@fmrp.usp.br

Research supported by $\mathrm{CNPq}$ and

FAPESP (Nos. 93/0525-0 and

00/09508-7).

Received September 18, 2006

Accepted May 21, 2007

$\ldots \ldots \ldots \ldots \ldots \ldots$

\begin{abstract}
${ }^{1}$ Departamento de Puericultura e Pediatria, Faculdade de Medicina de Ribeirão Preto, Universidade de São Paulo, Ribeirão Preto, SP, Brasil

${ }^{2}$ Faculdade de Medicina de Marília, Marília, SP, Brasil

${ }^{3}$ Departamento de Pediatria e Puericultura, Centro de Ciências da Saúde, Curso de Medicina, Universidade Federal de Santa Maria, Santa Maria, RS, Brasil ${ }^{4}$ Departamento de Saúde Pública, Universidade Federal do Maranhão, São Luís, MA, Brasil

${ }^{5}$ Departamento de Pediatria e Puericultura, Faculdade de Medicina, Universidade Federal do Rio Grande do Sul, Porto Alegre, RS, Brasil
\end{abstract}

\section{Abstract}

Obesity is one of the rising public health problems characterized as a risk factor for many chronic diseases in adulthood. Early life events such as intrauterine growth restriction, as well as life style, are associated with an increased prevalence of this disease. The present study was performed to determine if intrauterine growth restriction interacts with overweight at primary school age to affect body mass index (BMI) in young adults. From June 1, 1978 to May 31, 1979, 6827 singleton liveborns from Ribeirão Preto, São Paulo State, Brazil, corresponding to $98 \%$ of all births at the 8 maternity hospitals, were examined and their mothers were interviewed. Samples from the initial cohort were examined again at primary school age ( 8 to 11 years of age) and at the time of military service (18 years of age). There were 519 male individuals with complete measurements taken in the three surveys. Intrauterine growth-restricted individuals had a BMI $0.68 \mathrm{~kg}$ / $\mathrm{m}^{2}$ lower than that of individuals who were not restricted $(95 \% \mathrm{CI}=$ -1.34 to -0.03 ) and overweight at primary school age showed a positive and strong effect on BMI at 18 years of age (coefficient 5.03, $95 \% \mathrm{CI}=4.27$ to 5.79$)$. However, the increase in BMI was much higher - $6.90 \mathrm{~kg} / \mathrm{m}^{2}$ - when the conscript had been born with intrauterine growth restriction and presented overweight at primary school age $(95 \% \mathrm{CI}=4.55$ to 9.26$)$. These findings indicate that the effect of intrauterine growth restriction on BMI at 18 years of age is modified by later weight gain during school age.

\section{Introduction}

Obesity is a serious public health problem and its prevalence is on the increase worldwide (1). During the past two decades, the prevalence of overweight has more than
Key words

- Intrauterine growth

- Overweight

- Body mass index

- Obesity restriction doubled among children and adolescents in the United States $(2,3)$. Obesity has been considered to be a "time bomb" ready to lead us to an explosion of non-communicable chronic diseases (4), since obesity is related to a number of these diseases. 
Brazil and Latin America in general are not exceptions to this obesity epidemic $(5,6)$. Although in these countries undernutrition and related diseases represent a severe public health problem, obesity and excessive central body fat are highly prevalent, affecting both high and low socioeconomic strata (7).

Although the theory that adult risk factors for non-communicable chronic diseases are related to behavioral factors associated with adult lifestyle is more generally accepted (8), other explanatory models for the etiology of chronic adulthood disease are proposed. The occurrence of intrauterine growth restriction (IUGR) has been considered to be critical for the development of diseases and obesity in adulthood (9). However, in the context of obesity, this critical period could be extended to the first months of life, or even to 5-7 years of age and adolescence (10). Therefore, two etiological models could be considered to explain the excess weight gain. First, the "life course approach", which implies that cumulative exposures or aggressions such as disease and/or an unfavorable environment and behavior during the course of life increase the risk of chronic diseases and mortality $(8,11$, 12). Second, the "fetal origin hypothesis", stated by Barker (9) and amplified by Lucas $(13,14)$, who introduced the concept of "programming": an early stimulus or insult at a critical period could lead to impaired function of a structure or to the "setting" of a physiologic system. This means that environmental factors act in early life to program the risks for adverse health outcomes in adult life (9).

The effect of intrauterine and childhood growth on later body composition has been mainly studied in developed countries, whereas studies in developing countries, where the prevalence of IUGR is very much higher than in developed ones, are scarce. Therefore, several questions still remain to be answered. Can IUGR and overweight in childhood interfere with body mass index
(BMI) in young adulthood? Is there any link between weight in childhood and in adulthood? Does IUGR interact with overweight in childhood to determine BMI in adults? Are birth conditions related to BMI? We conducted the present study in order to address these questions.

\section{Subjects and Methods}

From June 1, 1978 to May 31, 1979, 9067 liveborns from Ribeirão Preto, São Paulo State, Brazil, corresponding to $98 \%$ of all births at the 8 maternity hospitals, were examined and their mothers were interviewed. Details of the initial study have been published elsewhere $(15,16)$. Soon after delivery and after giving written informed consent, mothers answered a standardized questionnaire which included the following variables: birth weight, duration of gestation, birth order, maternal age, schooling, marital status at the time of delivery, and maternal smoking during pregnancy. Newborns were weighed naked on weekly calibrated scales with 10-g precision according to standardized techniques $(17,18)$. The study population comprised 9067 live births, 6973 of them being from mothers who were resident in the municipality. Of these, 6827 were singletons and 3511 were males.

A sample of $50 \%$ of the participants of the initial cohort was sought from September 1987 to November 1989 in the primary schools of the city among children enrolled in 1st to 4th grade (19). A sample of 1512 boys was obtained, corresponding to $43.1 \%$ of the total. As military enlistment at 18 years of age is compulsory in Brazil and military sources report that about $70 \%$ of the eligible population for enlistment effectively report to the draft board, a study was conducted in 1996 and 1997 involving only males belonging to the initial cohort at the time of military service (20). A sample of 2048 individuals $(61 \%$ of the total after the exclusion of 142 known deaths in the first 
year of life) was interviewed at the time of military service.

Anthropometric measurements (weight and height) were made at primary school age by trained personnel according to standardized techniques (18). Age at the time of measurement was also recorded. At 18 years of age the measurements were collected from army records. The measurements were made by military personnel according to the guidelines of the Brazilian Army Ministry (21). All subjects had their height recorded, but weight was recorded only for boys born in 1979 because the study began after the physical examination of boys born in 1978; for those, only height but not weight was registered in the army records. At both times (school and army enlistment), the boys were weighed while wearing light clothing on calibrated scales with 100 -g precision, and measured with a wood stadiometer, standing up straight and barefoot, with an approximation to the nearest centimeter. Consent was obtained from school directors and from the conscripts.

Of the 3511 singleton males of the initial cohort, after excluding 142 deaths in the first year of life, 267 individuals born preterm, and those who did not have information on birth weight or weight and/or height at primary school age or at the time of military enlistment because of absenteeism, 519 individuals had complete measurements made in the three surveys.

The variables obtained at birth for this study were: birth weight $(<2500 ; 2500 \vdash 3000$; $\geq 3000 \mathrm{~g})$; maternal age $(<20,20 \vdash 30, \geq 30$ years); maternal schooling in years $(<4,4 \vdash 8$, $8 \vdash 11,11 \vdash 15, \geq 15)$; maternal marital status (cohabiting and not cohabiting); maternal smoking during pregnancy (yes or no, regardless of the number of cigarettes); birth order (first, second, third, and more). The concept of IUGR was based on the birth weight ratio (BWR), which is the ratio between the newborn's weight and the mean weight for gestational age of the gender- specific reference curve (22). A BWR $\geq 0.85$ was taken to be no growth restriction and a BWR $<0.85$ was taken to be IUGR (23). Gestational age was calculated on the basis of the date of the last normal menstrual period reported by the mother.

The educational level of the conscripts was divided into three groups (24): $0 \vdash 5$ years, $5 \vdash 9$ years and $\geq 9$ years of schooling. BMI was calculated using the formula weight $(\mathrm{kg}) /$ height $\left(\mathrm{m}^{2}\right)\left(\mathrm{W} / \mathrm{H}^{2}\right)$. Overweight at primary school age was calculated as proposed by Cole et al. (25), who consider a cut-off point of $25 \mathrm{~kg} / \mathrm{m}^{2}$ for overweight and of 30 $\mathrm{kg} / \mathrm{m}^{2}$ for obesity at 18 years of age. The corresponding values for ages younger than 18 years were the following, all of them being specific for males: at 8 years, $18.4 \mathrm{~kg} /$ $\mathrm{m}^{2}$ for overweight and $21.6 \mathrm{~kg} / \mathrm{m}^{2}$ for obesity; at 9 years, 19.1 and $22.8 \mathrm{~kg} / \mathrm{m}^{2}$; at 10 years, 19.8 and $24.0 \mathrm{~kg} / \mathrm{m}^{2}$, and at 11 years, 20.6 and $25.1 \mathrm{~kg} / \mathrm{m}^{2}$. Overweight and obese boys were considered to have weight excess and will be named "overweight" for the purpose of the present study.

\section{Statistical analysis}

Multiple linear regressions were carried out to test the association of variables at birth, overweight at primary school age and conscripts' schooling with conscripts' BMI. Four models were applied (26), each adjusted for the variables at birth and conscripts' schooling level: early model, including only IUGR; late model, which included only overweight at primary school age; combined model, including both IUGR and overweight at primary school age; interaction model, which added to the combined model the interaction between IUGR and overweight at primary school age on conscripts' BMI.

\section{Results}

A total of $15.1 \%$ of the conscripts were 
Table 1. Mean body mass index (BMI), $95 \%$ confidence interval $(95 \% \mathrm{Cl})$ and number and percentage of overweight subjects among primary school age children.

\begin{tabular}{|c|c|c|c|c|}
\hline Age of schoolchildren & $\mathrm{N}(\%)$ & Mean BMI* & $95 \% \mathrm{Cl}$ & $\begin{array}{c}\text { Overweight } \\
\text { children }^{\star *} \mathrm{~N}(\%)\end{array}$ \\
\hline 8 years & $31(6.0 \%)$ & 15.8 & 15.0 to 16.5 & $2(6.5 \%)$ \\
\hline 9 years & $391(75.2 \%)$ & 17.1 & 16.8 to 17.4 & $62(15.9 \%)$ \\
\hline 10 years & $92(17.8 \%)$ & 17.3 & 16.6 to 18.0 & $14(15.2 \%)$ \\
\hline 11 years & $5(1.0 \%)$ & 17.6 & 14.5 to 20.7 & $0(0.0 \%)$ \\
\hline Total & $519(100 \%)$ & 17.1 & 16.8 to 17.3 & 78 (15.1\%) \\
\hline
\end{tabular}

${ }^{*} \mathrm{P}=0.064$ (ANOVA for mean differences); ${ }^{* *} \mathrm{P}=0.41\left(\chi^{2}\right.$ test for frequency differences).

Table 2. Comparison of some baseline characteristics of males from the entire 1978/ 79 Ribeirão Preto birth cohort and those interviewed at primary school age (8-11 years old) and at the time of military service (18 years old).

\begin{tabular}{|c|c|c|}
\hline Variables & $\begin{array}{l}\text { Males in the } 1978 / 79 \\
\text { birth cohort }(N=3102)\end{array}$ & $\begin{array}{l}\text { Males interviewed at time } \\
\text { of primary school and } \\
\text { military service }(\mathrm{N}=519)\end{array}$ \\
\hline
\end{tabular}

\begin{tabular}{|c|c|c|}
\hline \multicolumn{3}{|l|}{ Birth weight } \\
\hline$<2500 \mathrm{~g}$ & $68(2.2 \%)$ & $7(1.3 \%)$ \\
\hline $2500 \vdash 3000 \mathrm{~g}$ & $542(14.5 \%)$ & $86(16.6 \%)$ \\
\hline$\geq 3000 \mathrm{~g}$ & $2491(80.3 \%)$ & $426(82.1 \%)$ \\
\hline \multicolumn{3}{|c|}{ Intrauterine growth restriction } \\
\hline No & $2684(86.6 \%)$ & 437 (84.2\%) \\
\hline Yes & 417 (13.4\%) & $82(15.8 \%)$ \\
\hline \multicolumn{3}{|c|}{ Maternal age (years) ${ }^{*}$} \\
\hline$<20$ & $418(13.5 \%)$ & $49(9.5 \%)$ \\
\hline $20 \vdash 30$ & $1929(62.2 \%)$ & $339(65.3 \%)$ \\
\hline$\geq 30$ & $728(23.5 \%)$ & $131(25.2 \%)$ \\
\hline \multicolumn{3}{|c|}{ Maternal schooling (years) ${ }^{*}$} \\
\hline$<4$ & $701(22.6 \%)$ & $67(12.9 \%)$ \\
\hline $4 \vdash 8$ & $1353(43.6 \%)$ & $253(48.7 \%)$ \\
\hline $8 \vdash 11$ & $382(12.3 \%)$ & $71(13.7 \%)$ \\
\hline $11 \vdash 15$ & $375(12.1 \%)$ & $86(16.6 \%)$ \\
\hline$\geq 15$ & $218(7.0 \%)$ & $42(8.1 \%)$ \\
\hline \multicolumn{3}{|l|}{ Birth order } \\
\hline $1 \mathrm{st}$ & $1071(34.5 \%)$ & 207 (39.9\%) \\
\hline 2nd & $913(29.4 \%)$ & $157(30.3 \%)$ \\
\hline 3rd and more & $1038(33.5 \%)$ & $155(29.8 \%)$ \\
\hline \multicolumn{3}{|c|}{ Maternal smoking during pregnancy* } \\
\hline No & $2177(72.0 \%)$ & $396(76.3 \%)$ \\
\hline Yes & $845(28.0 \%)$ & $123(23.7 \%)$ \\
\hline \multicolumn{3}{|l|}{ Marital status* } \\
\hline Non-cohabiting & $200(6.5 \%)$ & $10(2.0 \%)$ \\
\hline Cohabiting & $2871(93.5 \%)$ & 509 (98.0\%) \\
\hline
\end{tabular}

Data are reported as number with percent in parentheses. The "not known" categories were excluded from the table.

${ }^{*} \mathrm{P}<0.05$ for the differences between males interviewed and not interviewed for each category of the variables $\left(\chi^{2}\right.$ test). overweight at primary school age (Table 1). Baseline characteristics were compared between the whole cohort and the subjects participating in the present study (Table 2). Participants were less likely to have been born to adolescent mothers or to mothers with a higher schooling level ( $\geq 15$ years). There was no difference between low birth weight $(<2500 \mathrm{~g})$ and IUGR between the two groups $(\mathrm{P}=0.385$ and $\mathrm{P}=0.150$, respectively). Participants tended to be the first child born in the family $(\mathrm{P}=0.079)$. Mothers of traced individuals were less likely to have smoked during pregnancy $(\mathrm{P}=0.044)$ or to have no companion at the time of the participant's birth $(\mathrm{P}<0.001)$.

The early multiple linear regression model showed that IUGR had a small negative effect on BMI at 18 years: intrauterine growth-restricted children had a BMI 0.68 $\mathrm{kg} / \mathrm{m}^{2}$ lower than those who were not restricted $(\mathrm{P}=0.041)$; maternal smoking during pregnancy had a strong positive effect on BMI. Conscripts of smoking mothers were almost $1 \mathrm{~kg} / \mathrm{m}^{2}$ heavier than those whose mothers did not smoke $(\mathrm{P}<0.001)$. Maternal schooling level had only a marginal positive effect $(\mathrm{P}=0.084)$. Only boys born to mothers with low schooling ( $<4$ years) had a higher BMI than their counterparts (coefficient $1.15,95 \% \mathrm{CI}=0.11$ to 2.20 ). In the late model, overweight at primary school age showed a positive and strong effect on BMI at 18 years of age (coefficient $5.03,95 \% \mathrm{CI}=$ 4.27 to 5.79). The combined model assessed the independent effect of having IUGR or being overweight at primary school age, and only the strong positive effect of being overweight remained significant (coefficient 5.02, $95 \% \mathrm{CI}=4.26$ to 5.78 ). The interaction between these two explanatory variables showed a marginally positive effect $(\mathrm{P}=$ 0.063 ) on conscripts' BMI (coefficient 2.43, $95 \% \mathrm{CI}=0.13$ to 4.99 ; Table 3 ).

If the conscript had been a non-restricted intrauterine growth child but had become overweight at primary school age, his BMI 
was $4.79 \mathrm{~kg} / \mathrm{m}^{2}$ higher than the BMI of those who were not overweight $(95 \% \mathrm{CI}=3.99$ to 5.58). However, the increase in BMI was much higher $-6.90 \mathrm{~kg} / \mathrm{m}^{2}$ - when the conscript had been born with IUGR and presented overweight at primary school age $(95 \% \mathrm{CI}=4.55$ to 9.26 ; Table 4$)$.

\section{Discussion}

This study identified a significant interaction between early factors (IUGR) and overweight at primary school age affecting BMI at 18 years of age. These findings indicate that the effect of intrauterine growth on BMI at 18 years of age is modified by later weight gain during school age. Therefore, a positive coefficient for weight during childhood suggests that weight gain in the first years of life and not weight at this age is important in programming BMI at 18 years of age.

Considering the programming concept, the present study reinforces the hypothesis that hormonal/metabolic programming induced by early experience could influence BMI in later life. After controlling for social and environmental variables, the findings point to a significant negative influence of IUGR on BMI in young adults, although the size of the effect is small.

The influence of birth weight on BMI has been already identified in other studies (27, 28 ), and its effect may be modified by later gain in fat body mass. However, weight at 1 year of age was associated with adult fat mass, suggesting that postnatal environmental factors, such as infant feeding, could be more important than prenatal factors for the development of adult adiposity (28). On the other hand, some studies have noted a significant association between IUGR and increase in fat mass in adulthood (29). It seems that prolonged catch-up of weight in individuals born small for gestational age can lead to a significant increase in adiposity in adulthood due to metabolic changes such as
Table 3. Final multiple linear regression models for the body mass index of conscripts.

\begin{tabular}{|c|c|c|}
\hline Models & Coefficient & $95 \%$ confidence interva \\
\hline \multicolumn{3}{|l|}{ Early model ${ }^{1}$} \\
\hline \multicolumn{3}{|l|}{ IUGR* } \\
\hline \multicolumn{3}{|l|}{ No } \\
\hline Yes & -0.68 & -1.34 to -0.03 \\
\hline \multicolumn{3}{|l|}{ Maternal smoking* } \\
\hline \multicolumn{3}{|l|}{ No } \\
\hline Yes & 0.94 & 0.40 to 1.49 \\
\hline \multicolumn{3}{|l|}{ Maternal schooling } \\
\hline \multicolumn{3}{|l|}{$\geq 15$} \\
\hline $11 \vdash 15$ & -0.08 & -0.75 to 0.60 \\
\hline $8 \vdash 11$ & 0.29 & -0.56 to 1.13 \\
\hline $4 \vdash 8$ & 0.45 & -0.40 to 1.30 \\
\hline$<4$ & 1.15 & 0.11 to 2.20 \\
\hline \multicolumn{3}{|l|}{ Late mode ${ }^{2}$} \\
\hline \multicolumn{3}{|l|}{ Overweight at school age ${ }^{\star}$} \\
\hline \multicolumn{3}{|l|}{ No } \\
\hline Yes & 5.03 & 4.27 to 5.79 \\
\hline \multicolumn{3}{|l|}{ Combined model ${ }^{3}$} \\
\hline \multicolumn{3}{|l|}{ IUGR } \\
\hline \multicolumn{3}{|l|}{ No } \\
\hline Yes & -0.09 & -0.84 to 0.65 \\
\hline \multicolumn{3}{|l|}{ Overweight at school age* } \\
\hline \multicolumn{3}{|l|}{ No } \\
\hline Yes & 5.02 & 4.26 to 5.78 \\
\hline \multicolumn{3}{|l|}{ Interaction model ${ }^{4}$} \\
\hline \multicolumn{3}{|l|}{ IUGR } \\
\hline \multicolumn{3}{|l|}{ No } \\
\hline Yes & -0.32 & -1.10 to 0.46 \\
\hline \multicolumn{3}{|l|}{ Overweight at school age* } \\
\hline \multicolumn{3}{|l|}{ No } \\
\hline Yes & 4.79 & 3.99 to 5.58 \\
\hline Interaction IUGR overweight* & 2.43 & -0.13 to 4.99 \\
\hline
\end{tabular}

Coefficients derived from the multiple linear regression models, expressing the difference in BMl at 18 years of age in $\mathrm{kg} / \mathrm{m}^{2}$ comparing the "yes" category for each variable with the baseline category "no". "Early model: adjusted for intrauterine growth restriction (IUGR) and maternal variables at birth (age, schooling, marital status, smoking habit), and conscript birth order and schooling. ${ }^{2}$ Late model: adjusted for overweight at school age and for all other variables. ${ }^{3}$ Combined model: adjusted for IUGR, overweight at school age and all other variables. ${ }^{4}$ Interaction model: interaction term between IUGR and overweight at school age added to the combined model.

${ }^{*} \mathrm{P}<0.05$

Table 4. Interaction between intrauterine growth restriction (IUGR) and overweight at primary school age on conscript body mass index (BMI) in the multiple linear regression model.

\begin{tabular}{lccr}
\hline Variable $^{1}$ & $\mathrm{~N}(\%)$ & Coefficient $^{2}$ & $95 \% \mathrm{Cl}$ \\
\hline Non-IUGR and non-overweight & $366(70.5 \%)$ & & \\
IUGR and non-overweight & $75(14.5 \%)$ & -0.32 & -1.10 to 0.46 \\
Non-IUGR and overweight & $71(13.7 \%)$ & 4.79 & 3.99 to 5.58 \\
IUGR and overweight & $7(1.3)$ & 6.90 & 4.55 to 9.26 \\
\hline
\end{tabular}

${ }^{1}$ Adjusted for maternal variables at birth (age, schooling, marital status, smoking habit) and conscript birth order and schooling for a total of 519 individuals. ${ }^{2}$ Coefficient derived from the multiple linear regression model. It expresses the difference in BMI at 18 years of age in $\mathrm{kg} / \mathrm{m}^{2}$ comparing the three exposed categories (IUGR and nonoverweight, non-IUGR and overweight and IUGR and overweight) with the baseline category (non-IUGR and non-overweight). ${ }^{*} \mathrm{P}<0.001$. 
insulin, leptin and adiponectin resistance (30).

Previous studies have identified the influence of discrete growth pattern modifications on BMI and body composition later in life, demonstrating that events which occur during the growth process can play a role in the etiology of diseases in adult life $(31,32)$. Regarding BMI, late catch-up growth in childhood is associated with a significant increase in fatness and obesity risk later in life, supporting the notion that childhood represents an important period in the etiology of obesity (33) and showing the importance of environmental factors that influence the energy balance in childhood (34).

In the present study, the effects of the growth pattern were evident when we evaluated the effect of IUGR associated with the presence of overweight at primary school age on the BMI at 18 years of age, adjusted for maternal variables, birth order and conscript schooling. Although the number of children born with IUGR and presenting overweight at school age was small (only 7 cases), the effect of such interaction on the BMI at 18 years of age was strongly positive and significant.

The results allow us to suggest that a sequence of linked events mediated by the environment was involved in programming the pattern of weight gain in young adults. Therefore, the growth patterns evoked by the two previous distinct etiologic models (Life Course Approach and Fetal Origin Hypothesis) appear to be arbitrary since both played a significant role influencing the pattern of BMI in this sample (35). The school boys who had born with IUGR and became overweight during childhood were the ones presenting the greatest BMI scores at 18 years of age.

Some limitations of this study should be pointed out. The attrition rate was very high $(83 \%)$ due to limitations in funding to follow individuals in developing countries. How- ever, there was no difference between traced and non-traced individuals with respect to IUGR although traced individuals were better off than those not followed up, a fact that may have underestimated the effect observed here. The study was restricted to males living in an urban area and this may have led to an overestimation of mean BMI, which is higher in urban areas in Brazil (36). The lack of information regarding parental weight and height did not allow us to investigate genetic influences on the BMI of young adults. The high infant mortality rate among low birth weight newborns may have contributed to an underestimation of mean BMI among individuals born with low birth weight or with IUGR. In addition, the lack of information on dietary intake and activity level did not allow us to examine the influence of these factors on BMI. Finally, poor health and social disadvantages could have been the reasons for not enlisting in the army, possibly decreasing the estimate of mean BMI among less privileged social strata at 18 years of age (20).

Most of the limitations described here point to an underestimation of the identified effect, which reinforces our findings. In addition, to our knowledge, this is the first study performed in Brazil that evaluated in a prospective fashion, at three different times in life the influence of biologic and social variables on the BMI at primary school age and during young adulthood.

In conclusion, the fetal programming hypothesis and the life-course approach hypothesis by themselves cannot predict BMI at adulthood. We demonstrated that the effect of intrauterine growth on BMI in young adults is modified by later growth during childhood. This interaction demonstrates the necessity of measures targeted at IUGR children in order to prevent them from developing overweight during childhood with a consequent high BMI in adult life. 


\section{References}

1. World Heath Organization. Obesity: preventing and managing the global epidemic. Report of a WHO consultation on obesity. Geneva: WHO; 1997.

2. Flegal KM, Carroll MD, Kuczmarski RJ, Johnson CL. Overweight and obesity in the United States: prevalence and trends, 1960-1994. Int J Obes Relat Metab Disord 1998; 22: 39-47.

3. Ogden CL, Carroll MD, Curtin LR, McDowell MA, Tabak CJ, Flegal $\mathrm{KM}$. Prevalence of overweight and obesity in the United States, 1999-2004. JAMA 2006; 295: 1549-1555.

4. Bray GA. Obesity: a time bomb to be defused. Lancet 1998; 352 : 160-161.

5. Saldiva SR, Escuder MM, Venancio SI, Benicio MH. Prevalence of obesity in preschool children from five towns in São Paulo State, Brazil. Cad Saúde Pública 2004; 20: 1627-1632.

6. Rivera JA, Barquera S, Gonzalez-Cossio T, Olaiz G, Sepulveda J. Nutrition transition in Mexico and in other Latin American countries. Nutr Rev 2004; 62: S149-S157.

7. Arteaga H, Dos Santos JE, Dutra de Oliveira JE. Obesity among schoolchildren of different socioeconomic levels in a developing country. Int J Obes 1982; 6: 291-297.

8. Kuh D, Ben-Shlomo Y. A life course approach to chronic disease epidemiology. New York: Oxford University Press Inc.; 1997.

9. Barker DJ. Fetal origins of coronary heart disease. BMJ 1995; 311: 171-174.

10. Dietz WH. Critical periods in childhood for the development of obesity. Am J Clin Nutr 1994; 59: 955-959.

11. Ben-Shlomo $Y$, Smith GD. Deprivation in infancy or in adult life: which is more important for mortality risk? Lancet 1991; 337: 530534.

12. Frankel S, Elwood P, Sweetnam P, Yarnell J, Smith GD. Birthweight, body-mass index in middle age, and incident coronary heart disease. Lancet 1996; 348: 1478-1480.

13. Lucas A. Programming by early nutrition in man. In: CIBA Foundation Symposium 156 (Editor), The childhood environment and disease. Chichester: John Wiley; 1991. p 38-55.

14. Singhal A, Lucas A. Early origins of cardiovascular disease: is there a unifying hypothesis? Lancet 2004; 363: 1642-1645.

15. Barbieri MA, Gomes UA, Barros Filho AA, Bettiol H, Almeida LEA, Silva AAM. Saúde perinatal em Ribeirão Preto, SP, Brasil: a questão do método. Cad Saúde Públ 1989; 5: 376-387.

16. Cardoso VC, Simões VMF, Barbieri MA, Silva AAM, Bettiol H, Alves MTSSB, et al. Profile of three Brazilian birth cohort studies in Ribeirão Preto, SP and São Luís, MA. Braz J Med Biol Res 2007; 40: 1165-1176.

17. Davies DP, Holding RE. Neonatometer: a new infant length measurer. Arch Dis Child 1972; 47: 938-940.

18. Cameron N. The methods of auxological anthropometry. In: Falkner F, Tanner JM (Editors), Human growth. A comprehensive treatise. Methodology: ecological, genetic, and nutritional effects on growth. Vol 3. 2nd edn. New York: Plenum Press; 1985. p 3-46.

19. Bettiol H, Barbieri MA, Gomes UA, Gutierrez MR. School children's growth in Ribeirão Preto, Brazil. Eighth International Congress of Auxology. June 29-July 2; Philadelphia. 1997. p 26-27.

20. Haeffner LS, Barbieri MA, Rona RJ, Bettiol H, Silva AA. The relative strength of weight and length at birth in contrast to social factors as determinants of height at 18 years in Brazil. Ann Hum Biol 2002; 29: 627-640.

21. Ministério do Exército DGP. Sistema de recrutamento para o serviço militar inicial. Normas de procedimento das CS - Posto de inspeção de saúde. Brasília: Ministério do Exército; 1991.

22. Williams RL, Creasy RK, Cunningham GC, Hawes WE, Norris FD, Tashiro M. Fetal growth and perinatal viability in California. Obstet Gynecol 1982; 59: 624-632.

23. Kramer MS, Platt $\mathrm{R}$, Yang $\mathrm{H}$, McNamara $\mathrm{H}$, Usher $\mathrm{RH}$. Are all growth-restricted newborns created equal(Iy)? Pediatrics 1999; 103: 599-602.

24. Barata BR. Definições e mensuração da pobreza na região metropolitana de São Paulo: uma abordagem multissetorial. In: Barata BR (Editor), Condições de vida e situação de saúde. Rio de Janeiro: ABRASCO; 1997. p 197-249.

25. Cole TJ, Bellizzi MC, Flegal KM, Dietz WH. Establishing a standard definition for child overweight and obesity worldwide: international survey. BMJ 2000; 320: 1240-1243.

26. Lucas A, Fewtrell MS, Cole TJ. Fetal origins of adult disease - the hypothesis revisited. BMJ 1999; 319: 245-249.

27. Rasmussen $F$, Johansson $M$. The relation of weight, length and ponderal index at birth to body mass index and overweight among 18-year-old males in Sweden. Eur J Epidemiol 1998; 14: 373-380.

28. Sayer AA, Syddall HE, Dennison EM, Gilbody HJ, Duggleby SL, Cooper $\mathrm{C}$, et al. Birth weight, weight at $1 \mathrm{y}$ of age, and body composition in older men: findings from the Hertfordshire Cohort Study. Am J Clin Nutr 2004; 80: 199-203.

29. Jaquet D, Gaboriau A, Czernichow P, Levy-Marchal C. Insulin resistance early in adulthood in subjects born with intrauterine growth retardation. J Clin Endocrinol Metab 2000; 85: 1401-1406.

30. Ong KK, Petry CJ, Emmett PM, Sandhu MS, Kiess W, Hales CN, et al. Insulin sensitivity and secretion in normal children related to size at birth, postnatal growth, and plasma insulin-like growth factor-I levels. Diabetologia 2004; 47: 1064-1070.

31. Viner RM, Cole TJ. Who changes body mass between adolescence and adulthood? Factors predicting change in BMI between 16 years and 30 years in the 1970 British Birth Cohort. Int J Obes 2006; 30: 1368-1374.

32. Parsons TJ, Manor O, Power C. Physical activity and change in body mass index from adolescence to mid-adulthood in the 1958 British cohort. Int J Epidemiol 2006; 35: 197-204.

33. Wells JC, Hallal PC, Wright A, Singhal A, Victora CG. Fetal, infant and childhood growth: relationships with body composition in Brazilian boys aged 9 years. Int $J$ Obes 2005; 29: 1192-1198.

34. Monteiro PO, Victora CG, Barros FC, Monteiro LM. Birth size, early childhood growth, and adolescent obesity in a Brazilian birth cohort. Int J Obes Relat Metab Disord 2003; 27: 1274-1282.

35. Boulton TJC. The notion of tracking. In: Boulton J, Laron Z, Rey J (Editors), Long-term consequences of early feeding. Nestlé Nutrition Workshop Series, 36; 1996. p 99-111.

36. Popkin BM. The nutrition transition in low-income countries: an emerging crisis. Nutr Rev 1994; 52: 285-298. 


\title{
Psychobiology Graduate Program
}

The Department of Psychobiology, Escola Paulista de Medicina, is a WHO Collaborating Center for research and training in Mental Health, and has laboratories for biochemical, physiological and behavioral research. It also has a Clinical Psychobiology Research Center, with a 16-bed inpatient unit, sleep and biofeedback laboratories, a clinical analysis laboratory, and an outpatient clinic. This Center provides consulting services to the federal and state governments.

Major research areas:

\author{
ANXIETY AND STRESS \\ BASIC AND CLINICAL PSYCHOPHARMACOLOGY \\ DRUG AND ALCOHOL DEPENDENCE \\ LEARNING AND MEMORY \\ MOOD DISORDERS \\ SLEEP BIOLOGY AND MEDICINE
}

The Department of Psychobiology, EPM, offers basic courses to undergraduate students of Medicine and Biological Sciences, a clinical psychopharmacology course to residents in Psychiatry, and a Psychobiology Graduate Program designed to train students for academic, research, and clinical activities.

The Program is partially supported by AFIP (Associação Fundo de Incentivo à

Psicofarmacologia), a non-profit organization. This advertisement is financed by AFIP.

For more information please contact:

Departamento de Psicobiologia

Escola Paulista de Medicina

A/C Secretaria do Curso de Pós-Graduação

Rua Botucatu, $862,1^{\circ}$ andar

CEP 04023-062 São Paulo, SP, Brasil

Tel. $\operatorname{0XX}(11) 21490155$ 